\title{
Micro-abrasion wear testing of triode plasma diffusion and duplex treated Ti-6Al-4V alloy
}

\author{
G. Cassar ${ }^{\mathrm{a}, *}$, S. Banfield ${ }^{\mathrm{a}, \mathrm{b}}$, J.C. Avelar-Batista Wilson ${ }^{\mathrm{b}}$, J. Housden $^{\mathrm{b}}$, A. Matthews ${ }^{\mathrm{a}}$, A. Leyland ${ }^{\mathrm{a}}$ \\ a Department of Materials Science and Engineering, University of Sheffield, Sir Robert Hadfield Building, Mappin St., Sheffield S1 3JD, UK \\ ${ }^{\mathrm{b}}$ Tecvac Ltd., Buckingway Business Park, Swavesey, Cambridge CB24 4UG, UK
}

\section{A R T I C L E I N F O}

\section{Article history:}

Received 24 May 2011

Received in revised form 12 October 2011

Accepted 13 October 2011

Available online $\mathrm{xxx}$

\section{Keywords:}

Micro-abrasion wear

TiN

CrAIN

WC/C

Triode plasma diffusion

\begin{abstract}
A B S T R A C T
In this paper micro-abrasion wear testing is used to evaluate the wear resistance of triode plasma diffusion-treated, single-layered TiN-, CrAlN-, and WC/C-coated and duplex-diffusion and coated Ti-6Al-4V under uniform three-body rolling abrasion. Nanoindentation, Knoop microhardness, mechanical surface profilometry, optical microscopy, scanning electron microscopy and atomic force microscopy, were used to characterise the surfaces under investigation. Optimum testing conditions for rolling abrasion were established by varying the test parameters and resultant severity of contact. Very low normal loads and high volume fractions of particles in the abrasive slurry are necessary to obtain predictable and reproducible results. Relatively coarse $\mathrm{SiC}$ abrasive particles, having a mean diameter of around $3 \mu \mathrm{m}$, appear more suitable for micro-abrasion testing of the samples investigated, compared to finer $\mathrm{Al}_{2} \mathrm{O}_{3}$ particles. Problems associated with the measurement of the scar volume and subsequent calculation of the wear rate for hard coatings deposited on relatively soft metals like titanium are identified, and suitable testing and measurement techniques are suggested. Three-dimensional wear scar maps generated by mechanical stylus profilometry were used to measure the wear volumes. Under the test conditions used, wear coefficients can be determined from perforating and non-perforating tests, although perforating tests provide more consistent results. Triode plasma diffusion treatments, plasma-assisted (PA) PVD TiN and PAPVD CrAlN can reduce the specific wear rate of Ti-6Al-4V, while PACVD-based WC/C coatings do not provide suitable protection against abrasive wear. The combination of triode plasma oxynitriding diffusion treatments and PVD coatings to create duplex treatments can also lead to further reductions in the coating wear coefficient when compared to non-duplex coatings deposited on non-pretreated substrates.
\end{abstract}

(C) 2011 Elsevier B.V. All rights reserved.

\section{Introduction}

Titanium and its alloys exhibit many excellent mechanical and physical properties, making them ideal for a variety of applications; however, poor tribological performance has historically been a significant constraint to their wider use in engineering applications (such as for bearing surface and moving parts). The recent use of surface engineering techniques, particularly ceramic hard coatings and surface thermochemical conversion treatments, has allowed the expansion of the range of possible fields of application to those which include relative motion between components in contact.

Recently, triode plasma diffusion treatments, in 'duplex' combination with hard PVD coatings, have been demonstrated as

\footnotetext{
* Corresponding author. Tel.: +356 2340 2140; fax: +356 21343577.

E-mail address: glenn.cassar@um.edu.mt (G. Cassar).
}

suitable techniques capable of substantially improving the wear resistance of $\mathrm{Ti}-6 \mathrm{Al}-4 \mathrm{~V}$ under reciprocating sliding wear testing - a predominantly two-body (2B) abrasive test [1]. However, micro-abrasion testing is very different to 'pin-on-flat' type wear tests, in that it involves little plastic deformation of the substrate below the contact region. Therefore, the technique offers an insight to the performance of surface treated test pieces under very different operating conditions. Furthermore, in most practical applications three-body (3B) wear is often prevalent due to unavoidable presence of contaminant particles, while two-body wear can be avoided by ensuring smooth bearing surfaces, by effective lubrication and by appropriate running-in of the mating components. Thus, ensuring effective abrasive wear resistance is essential in making Ti alloys suitable for a wider range of applications; therefore knowledge about the abrasive wear resistance of surface hardened titanium can play a decisive role. Particularly in the case of coated components, the presence of hard debris may be an unfortunate consequence of the surface engineering 
treatment. Localized premature coating failure, and/or poor adhesion can initiate rapid failure of the component if the remaining surface is susceptible to $3 \mathrm{~B}$ wear.

The ball-cratering based micro-scale abrasion wear test has evolved as an established method to determine the abrasive wear properties of coatings and bulk materials - although little work has yet been dedicated to the resistance to abrasion wear of titanium alloys, particularly when such materials are modified using surface engineering techniques. In the 'fixed-ball' configuration of the test, a ball is rotated while being pressed against the sample in the presence of an abrasive slurry - typically a fine SiC powder dispersed in water. This produces a circular impression in the sample that is later measured to determine the specific wear rate of the coating and substrate material (in perforating tests).

Depending on the test conditions selected and the ball and sample material, the dominant wear modes observed in micro-abrasion tests are two-body and three-body abrasion. Three-body abrasion results when the particles roll in the contact region while twobody abrasion occurs when the particles slide in the contact region. Craters where particle rolling motion predominates are characterised by a uniform multiply - indented and heavily deformed topography as a result of micro-chipping and indentation damage by multiple abrasives [2]. Conversely, in two-body abrasion, the particles are rigidly attached to the ball surface by some degree of embedment, and this condition will produce multiple fine, parallel grooves in the counterface, clearly aligned in the direction of ball rotation [3].

The prevalent wear mode has a significant effect on the wear rate and can also affect the reproducibility of the test results [4]. Adachi and Hutchings [5] have shown that specific wear rates in the rolling abrasion regime (3B) are relatively insensitive to test conditions, such as load and abrasive volume fraction, whereas the wear rates for grooving abrasion (2B) are much more strongly dependent on the operating conditions. Also, conditions typically leading to $2 \mathrm{~B}$ abrasion can cause an atypical flow of slurry around the contact area. This leads to non-spherical wear scars, characterised by a ridge of specimen material in the centre of the scar, parallel to the sliding direction [6]. The resultant wear rate is therefore unpredictable. Furthermore, the relationship between load and wear volume per unit sliding distance is often non-linear for $2 \mathrm{~B}$ conditions. In contrast, this wear volume is in general found to be directly proportional to the normal load for 3B abrasion [3]. Thus, test conditions favouring rolling abrasive wear were considered important for obtaining meaningful results from this work.

Adachi and Hutchings [7] demonstrated that the transition from one wear mode to the other can be expressed by a critical value of a dimensionless quantity known as severity of contact, $S_{c}$. The severity of contact, can be written as:

$S_{c}=\frac{W}{A V_{f} H^{\prime}}$

where $W$ is the normal load, $V_{f}$ is the volume fraction of abrasive in solution, $A$ is the interaction area (approximated to the wear scar area) and $H^{\prime}$ is the effective hardness. In turn, $A$ and $H^{\prime}$ are defined by Eqs. (2) and (3) respectively:

$A=\pi a^{\prime 2}=\pi\left(a^{2}+2 R D\right)$

where $a^{\prime}$ is the interaction radius, $a$ is the Hertzian contact radius, $R$ is the radius of the ball and $D$ is the diameter of the abrasive particles and

$\frac{1}{H^{\prime}}=\frac{1}{H_{s}}+\frac{1}{H_{b}}$

where $H_{s}$ and $H_{b}$ are the sample surface and ball hardness respectively.
Adachi and Hutchings [7] also proposed a wear-mode map which depicts the two wear regimes as function of $S_{c}$ and the hardness ratio, $H_{s} / H_{b}$. The transition between the two wear modes has been found to be controlled by the ratio of the sample to ball hardness such that $3 \mathrm{~B}$ rolling abrasion is expected to occur when:

$S_{c}=\frac{W}{A V_{f} H^{\prime}} \leq \alpha\left(\frac{H_{s}}{H_{b}}\right)^{\beta}$

where $\alpha$ and $\beta$ are empirical constants ( $\alpha \approx 0.0076, \beta \approx-0.49$ ).

Clearly, this definition of $S_{c}$ implies that a lower value promotes the occurrence of rolling abrasion over grooving abrasion.

Once the tests have been performed the sample and coating specific wear rates have to be calculated. Several different methods for the determination of specific wear rates have been proposed by different authors. A critical review and comparison in terms of accuracy can be found in [8]. These methods are all derived from Archard's equation for sliding wear:

$W S=\frac{V}{\kappa}$

where $V$ is the total wear scar volume, $S$ is the sliding distance and $\kappa$ is the specific wear rate or wear coefficient (conventionally quoted in units of $\mathrm{mm}^{3} / \mathrm{Nm}$ ).

Rutherford and Hutchings $[9,10]$ extended Eq. (5) to include the combined wear of both coating and substrate, each with independent specific wear coefficients; $\kappa_{c}$ for the coating, and $\kappa_{s}$ for the substrate associated with the coating and substrate wear scar volumes, $V_{c}$ and $V_{s}$ respectively. Thus for coated substrates, a combined wear equation can be written as:

$W S=\frac{V_{c}}{\kappa_{c}}+\frac{V_{s}}{\kappa_{S}}$

Eq. (6) can also be rewritten in terms of the total wear scar volume $\left(V=V_{c}+V_{S}\right)$, such that $\kappa_{c}$ and $\kappa_{s}$ are obtained from the gradient and intercept of a linear fit:

$\frac{W S}{V}=\left(\frac{1}{\kappa_{c}}-\frac{1}{\kappa_{S}}\right) \frac{V_{c}}{V}+\frac{1}{\kappa_{S}}$

\section{Experimental details}

The nominal chemical composition of the Ti-6Al-4V alloy used was $6.01 \mathrm{wt} . \% \mathrm{Al}, 4.08 \mathrm{wt} . \% \mathrm{~V}$, balance Ti. The test coupons had a core hardness of $375 \pm 10 \mathrm{HK}_{0.025}$ and were polished to a mirror finish, with a measured mean surface roughness $\left(R_{a}\right)$ of $0.03 \pm 0.01 \mu \mathrm{m}$.

The base material was diffusion-treated by triode plasma nitriding or combined oxidising/nitriding in a modified Tecvac IP70L commercial coating system, using a low-pressure d.c. triode configuration $[11,12]$ and additional radiative heating. Triode enhanced-plasma diffusion treatments were carried out at a substrate temperature of $700^{\circ} \mathrm{C}$ in a mixture of 0.7 partial pressure of nitrogen or oxygen and 0.3 partial pressure of argon, at a total gas pressure of $0.4 \mathrm{~Pa}$. The abbreviated designations of each diffusion treatment type are illustrated in Table 1. LHV-TPON processes carried out for $4 \mathrm{~h}$ included a first hour of oxidation at a low cathode voltage of $-200 \mathrm{~V}$, followed by nitriding at $-200 \mathrm{~V}$ for $2 \mathrm{~h}$, and a final hour of nitriding at a higher cathode bias of $-1000 \mathrm{~V}$.

Table 1

Sample designation system.

\begin{tabular}{ll}
\hline Bias potential & $\begin{array}{l}\text { Triode-plasma diffusion } \\
\text { process }\end{array}$ \\
\hline $\begin{array}{l}\text { Low voltage }(-200 \mathrm{~V})(\mathrm{LV}) \\
\text { High voltage }(-1000 \mathrm{~V})(\mathrm{HV})\end{array}$ & $\begin{array}{l}\text { Nitriding (TPN) } \\
\text { Low voltage followed by high } \\
\text { voltage treatment }(\mathrm{LHV})\end{array}$ \\
$\begin{array}{l}\text { Oxidation followed by } \\
\text { nitriding (TPON) }\end{array}$ \\
\hline
\end{tabular}


The specimens, untreated or diffusion-treated, were coated either with TiN deposited using an electron-beam plasma-assisted physical vapour deposition (EB PAPVD) system (Tecvac IP70 coater) or CrAlN deposited using a twin-EB PAPVD machine (Tecvac IP35 coater). Thermionic plasma enhancement was provided by an additional electron-emitting cathode in the form of a hot tungsten filament, biased at $-200 \mathrm{~V}$, positioned near the base of the chamber, adjacent to the vapour source(s). Samples were firstly diode sputter cleaned in Ar at $2.0 \pm 0.1 \mathrm{~Pa}$ chamber pressure and $1000 \mathrm{~V}$ substrate negative bias, then a thin interlayer with a thickness between 0.1 and $0.2 \mu \mathrm{m}$ was deposited ( $\mathrm{Ti}$ in the case of TiN, and $\mathrm{Cr}+\mathrm{CrN}$ for $\mathrm{CrAlN}$ ) under a pressure of $0.3 \mathrm{~Pa}$ and triode conditions. Finally, the ceramic coating layer was deposited for approximately $100 \mathrm{~min}$, to give a total thickness of $2.8 \pm 0.2 \mu \mathrm{m}$ in the case of TiN, and $2.0 \pm 0.2 \mu \mathrm{m}$ for CrAlN. During coating the maximum substrate temperature ranged between 400 and $450^{\circ} \mathrm{C}$.

$\mathrm{WC} / \mathrm{C}$ coatings were produced using a Tecvac d.c. unbalanced magnetron sputtering PVD machine. A $\sim 300 \mathrm{~nm} \mathrm{Cr}$ interlayer was first deposited and then a WC phase was grown using magnetron sputtering, whereas the $C$ phase was introduced simultaneously by plasma-assisted CVD from an acetylene $\left(\mathrm{C}_{2} \mathrm{H}_{2}\right)$ and Ar plasma. During coating deposition the substrate temperature ranged between 200 and $250^{\circ} \mathrm{C}$. The total thickness of WC/C coatings was $2.5 \pm 0.1 \mu \mathrm{m}$.

\subsection{Surface characterisation}

Knoop microindentation hardness measurements were performed on polished substrate cross-sections using a Mitutoyo HM microhardness tester, set at a load of $25 \mathrm{gf}(1 \mathrm{gf}=9.81 \mathrm{mN})$ and a $20 \mathrm{~s}$ dwell time. The test method used followed the relevant standard for Knoop hardness testing of metallic materials - BS EN ISO 4545-1:2005 [13]. Surface nanoindentation measurements were performed using a Hysitron Inc. Triboscope ${ }^{\mathrm{TM}}$ equipped with a Berkovich triangular-pyramidal diamond indenter. Fifteen indentations were made for each sample at maximum loads of around $10 \mathrm{mN}$ and $5 \mathrm{mN}$ for coatings and diffusion-treated samples, respectively.

Optical microscopy was carried out using a Polyvar Met research microscope fitted with Axio Cam (Zeiss) digital camera. A JEOL JSM 6400 scanning electron microscope (SEM) operated at $15-20 \mathrm{kV}$ was used for electron microscopy.

A Veeco Dektak 150 stylus profilometer was used to measure the sample surface roughness and wear scar volumes. The $12.5 \mu \mathrm{m}$ radius stylus tip was loaded with a force of $30 \mathrm{mg}$ and the scan duration was set such that the traversing resolution was better than $0.05 \mu \mathrm{m}$. The vertical resolution was less than $0.01 \mu \mathrm{m}$. Threedimensional (3D) maps were also obtained using multiple scans which were then integrated using Vision ${ }^{\circledR}$ 3D analysis software. The number of parallel scans was set such that a minimum lateral resolution of $25 \mu \mathrm{m}$ was obtained.

More detailed topography was obtained using a Digital Instruments Multimode Nanoscope IV atomic force microscope (AFM) with an e-scanner and rectangular silicon nitride (Olympus Co.) cantilevers which had been previously gold coated. The instrument was operated in contact mode, at a frequency of $1 \mathrm{~Hz}$ and an applied load of approximately $5 \mathrm{nN}$.

\subsection{Micro-abrasion wear testing}

Micro-abrasion testing was performed using a Plint TE-66 micro-scale abrasion tester. Preconditioned bearing steel balls were used [14], since smooth 'as-received' counterface balls have been proved to cause poor abrasive entrainment and in turn nonrepresentative tests $[15,16]$. A series of progressively longer tests was performed according to the methodology described in [14].

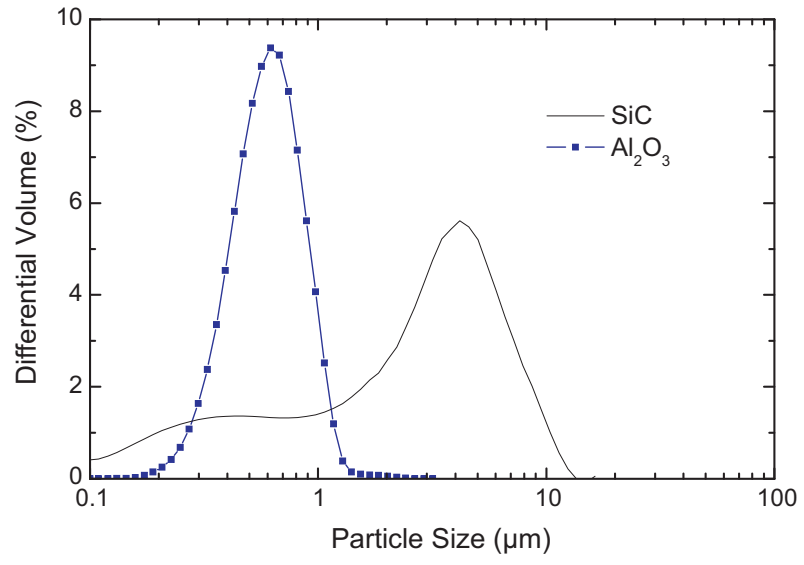

Fig. 1. Size distribution of $\mathrm{SiC}$ and $\mathrm{Al}_{2} \mathrm{O}_{3}$ particles used as abrasive.

Table 2

Test conditions used for micro-abrasion tests.

\begin{tabular}{ll}
\hline Normal force $(\mathrm{N})$ & 0.1 \\
Ball rotational speed $(\mathrm{rpm})$ & $\sim 76.4$ \\
Tangential sliding velocity $(\mathrm{m} / \mathrm{s})$ & 0.1 \\
Abrasive material & $\mathrm{SiC}$ - Grade P1200 (Logitech Ltd., UK) \\
Slurry concentration $(\mathrm{g} / \mathrm{ml})$ & 0.8 \\
Volume fraction & 0.24 \\
Mean particle size $(\mu \mathrm{m})$ & $3.1(\mathrm{~s}=2.7)$ \\
Abrasive carrier & Distilled water \\
Ball diameter $(\mathrm{mm})$ & 25 \\
Ball material & Bearing steel (SAE52100) \\
Ball hardness $(\mathrm{GPa})$ & 8.5 \\
No. of ball revolutions (revs) & $10,35,50,100,300,500,800$ \\
\hline
\end{tabular}

Between each test the ball was axially rotated slightly, such that no two tests used precisely the same circumferential band.

In order to formulate these testing parameters, a number of preliminary tests were performed. The chosen set of experimental conditions maintained a low value of contact severity $\left(S_{c}\right.$, Eq. (1)) during the tests, so as to consistently generate a predominantly $3 \mathrm{~B}$ abrasion mechanism and thus meaningful comparisons between the resulting wear rates could be made. Preliminary testing mainly included the use of different loads, particle volume fractions, and two types of abrasive particle ( $\mathrm{SiC}$ and $\mathrm{Al}_{2} \mathrm{O}_{3}$ ). Although $\mathrm{SiC}$ is overwhelmingly the more commonly used medium for such tests, the finer mean particle size of the $\mathrm{Al}_{2} \mathrm{O}_{3}$ (99.95\% pure from Alfa Aesar, USA) powder ( $0.61 \mu \mathrm{m}$ compared to $3.1 \mu \mathrm{m}$ of $\mathrm{SiC})$ was a better match to the thickness of the specific layers of interest in this work. The size distribution of both $\mathrm{SiC}$ and $\mathrm{Al}_{2} \mathrm{O}_{3}$ particles was assessed using laser granulometry (Beckman Coulter LS 130), for which results are presented in Fig. 1. Following the preliminary trials (discussed further in the following section) the experimental conditions were established (Table 2).

Finally, the volume of the wear craters produced needed to be evaluated; however, the variety of treatments tested in this work posed different concerns regarding the accuracy of the selected measurement and data analysis technique. For instance, for untreated and diffusion-treated specimens the relatively large $\mathrm{SiC}$ particles produced scars which typically lacked boundary definition. Furthermore, different samples exhibited scar shapes which deviated from the idealised hemispherical cap geometry. For these reasons the use of data analysis methods analogous to those developed by Rutherford and Hutchings $[9,10]$ were considered unsuitable, since these assume a wear scar profile which replicates that of the ball and would (in our case) introduce appreciable errors to the measured wear volume.

The use of 3D surface maps and Vision ${ }^{\circledR}$ 3D analysis software allowed very accurate profilometry measurement of the wear scar 

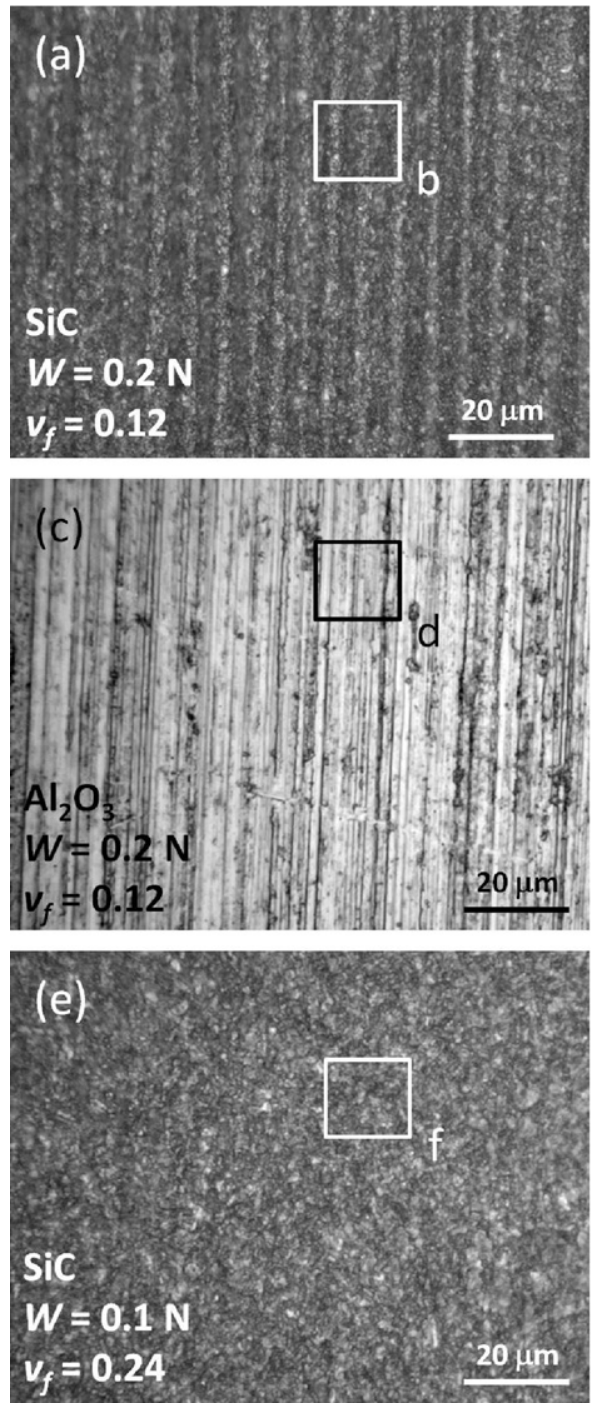
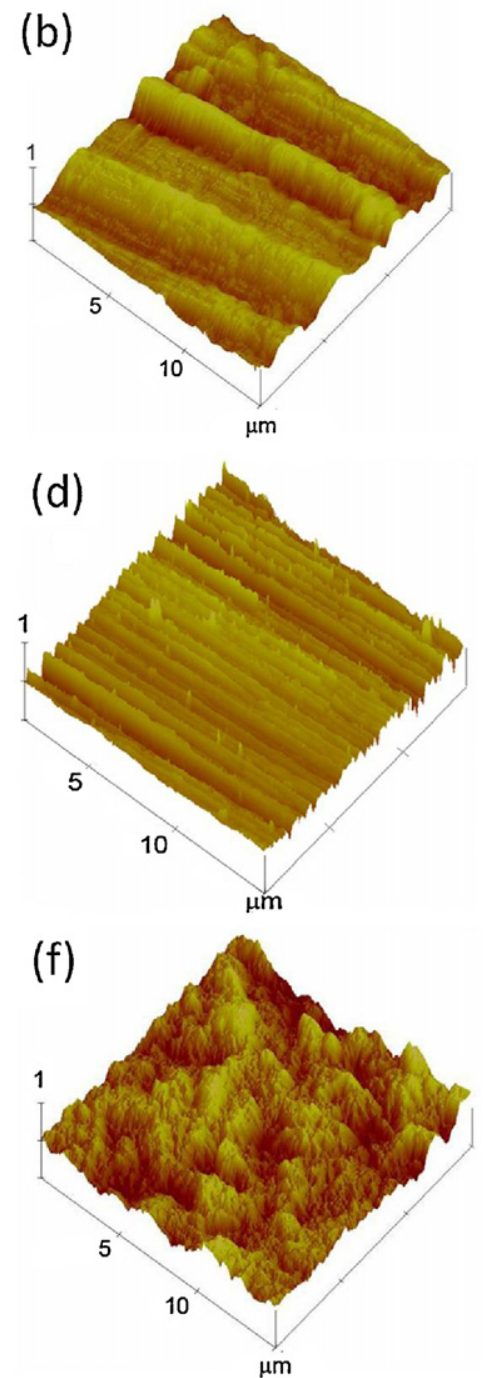

Fig. 2. Optical and AFM topographic images showing representative worn surfaces on Ti-6Al-4V.

volumes, i.e. the total crater wear volume $(V)$ and the individual coating $\left(V_{c}\right)$ and substrate $\left(V_{s}\right)$ volume components. This quantification method also allowed the use of very small (and relatively irregular in shape), non-perforating craters which would otherwise be expected to introduce unacceptably large errors. The precise value for each coating layer thickness needed to accurately measure $V_{c}$ and $V_{s}$ was obtained using very accurate ball-cratering with fine diamond abrasive (mean diameter $0.25 \mu \mathrm{m}$ ) [8] and also confirmed by SEM observation of coating fracture cross-sections.

The virtual model of the scar and its surrounding area was first digitally levelled and then the flat area well outside the crater volume was assigned as a reference datum. A second reference plane was set at a depth corresponding to the coating thickness. Subsequent volume measurements were taken by calculating the volume enclosed between the reference planes and the crater surface. In agreement with previous work [16], the volumes measured through profilometry, compared to those calculated through optical measurements, were consistently smaller.

Having accurately determined the values of $V, V_{s}$ and $V_{c}$, the specific wear rates of both coating and substrate were then extracted from a linear fit to the data using Eq. (7) and the resultant intercept and gradient of this line. The principal errors in this technique arise from the resolution of the 3D mapping and this was minimised by setting very fine scan intervals and maintaining the number of passes at a constant ratio to the size of the scar being mapped. The other possible source of error, when using this technique, is during the coating thickness measurement; however, this dimension can be obtained to very high accuracy levels using the above mentioned procedures.

\section{Results and discussion}

\subsection{Optimisation of test conditions for Ti-6Al-4V}

Abrasion scars produced on untreated Ti-6Al-4V exhibit either (i) unidirectional parallel grooves as shown in Fig. 2a-d, or (ii) a multiple indented surface topography with no noticeable directionality as shown in Fig. 2e and f. Both optical and AFM images show that the micro-cutting action of the abrasive leaves relatively deep trenches when the contact severity is sufficiently high to permit dragging of the particles into the contact. The size of these trenches is clearly comparable to the mean size of the abrasive used. The finer texture of the wear scars produced using $\mathrm{Al}_{2} \mathrm{O}_{3}$ (as opposed to $\mathrm{SiC}$ ) relates to the reduced mean diameter of the alumina particles $(0.61 \mu \mathrm{m}$, compared to $3.1 \mu \mathrm{m}$, respectively). Thus, wear scars could be identified as caused by one of the two wear mechanisms (2B or 3B abrasion), while a few showed central 


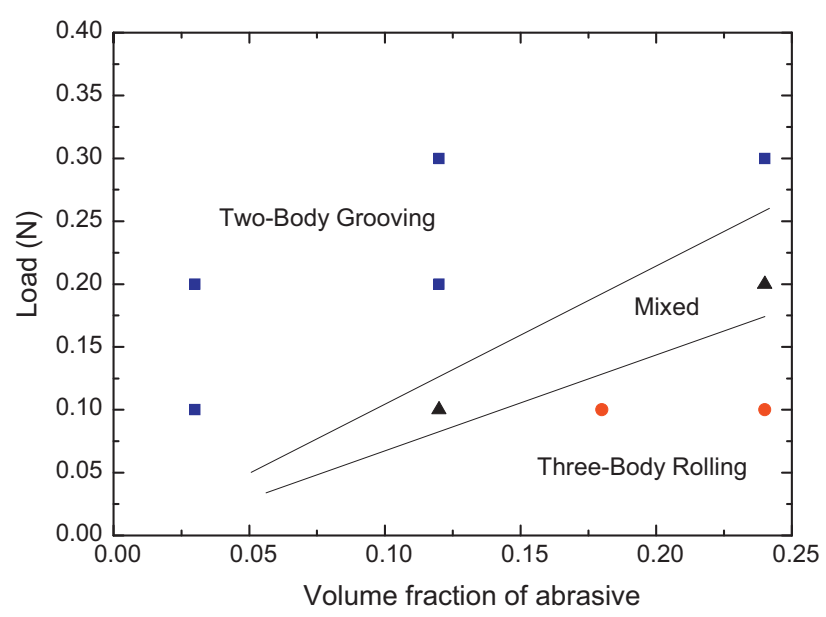

Fig. 3. Wear mechanism map for ball crater micro-scale abrasion of Ti-6Al-4V by SiC slurry.

regions with grooving features and fine multiple indentations at the outer periphery. These are referred to as 'mixed' (wear mode).

Fig. 3 shows the distribution of wear modes observed in several experiments for untreated Ti-6Al-4V abraded using SiC-based slurry. In accordance with the existing literature [17,18], abrasion tests at low loads below $0.3 \mathrm{~N}$, which promote a 3B wear mechanism, were performed. The wear mechanism map, presented in terms of applied load and slurry concentration, shows that the wear mode changed from $3 \mathrm{~B}$ to $2 \mathrm{~B}$ abrasion with an increase in normal load, $W$, and a decrease in volume fraction, $V_{f}$, of abrasive. Similar tests performed using finer $\mathrm{Al}_{2} \mathrm{O}_{3}$ showed that it was much more difficult to achieve a consistent $3 \mathrm{~B}$ wear mechanism. This concern would eventually be exaggerated when testing harder, diffusion-treated and/or coated substrates which, due to their higher hardness, would almost certainly result in two-body or mixed wear. This was attributed to three factors:

$1 \mathrm{Al}_{2} \mathrm{O}_{3}$ is around $20 \%$ more dense than $\mathrm{SiC}$ [19], and therefore the corresponding volume of $\mathrm{Al}_{2} \mathrm{O}_{3}$ for the same weight of powder is lower than $\mathrm{SiC}$. In turn, this leads to less solid entrapment within the contact area thereby increasing the net load per particle.

2 The mean size of the $\mathrm{Al}_{2} \mathrm{O}_{3}$ particles used in this work was $0.61 \mu \mathrm{m}$ i.e. $\sim 80 \%$ smaller than $\mathrm{SiC}$ particles. Once again, this largely increases the local contact pressure exerted on each particle, promoting the transition to two-body wear.

3 A maximum of $0.6 \mathrm{~g} / \mathrm{ml}\left(V_{f}=\sim 0.2\right)$ of $\mathrm{Al}_{2} \mathrm{O}_{3}$ could be kept in suspension in water without the use of deflocculants. The increased tendency to agglomeration can be explained by the higher specific surface area associated with the submicron diameter particles.

Furthermore, 2D traces generated by profilometry scans of scars created using $\mathrm{Al}_{2} \mathrm{O}_{3}$ indicate that the shape of these varied significantly from the expected hemi-spherical geometry. This is likely to be as a result of a non-uniform flow of abrasive slurry around the ball contact area. The scan profile and observations during testing suggest that the slurry accumulates at the top region of the ball. This results in an elongation of the scar in the direction parallel to the ball rotation. These results clearly favoured the use of SiC as opposed to $\mathrm{Al}_{2} \mathrm{O}_{3}$.

The test parameters plotted in Fig. 3 have been superimposed onto the abrasion mode map developed by Adachi and Hutchings [7], Fig. 4. In order to determine the test severity of contact, $S_{c}$, the interaction area was calculated using Eq. (4) and the value of the interaction area was defined by the measured diameter of the

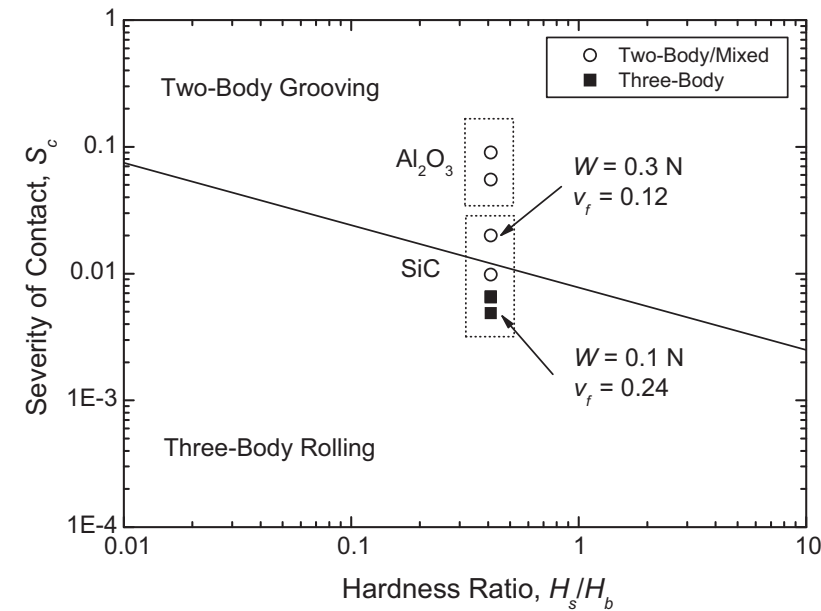

Fig. 4. Wear mode diagram (after [7]) as a function of $S_{c}$ and the substrate to ball hardness ratio, with the superimposed test conditions used for this study.

actual scars (produced after 10 revolutions) rather than computed using Eq. (2). The contact area values predicted from Eq. (2) were found to reduce the 'real' value of $S_{c}$ as these calculated values of the contact surface area were clearly overestimated. The difference was attributed to two main factors; (i) the shape of the $\mathrm{SiC}$ particles strongly deviates from spherical (Fig. 5) and therefore the longer particles will tend to bear a higher proportion of the applied load, resulting in high load per particle and (ii) the negatively skewed particle size distribution shows the presence of a significant number of smaller particles; Fig. 1 shows that around $25 \%$ of the particles are smaller than $1 \mu \mathrm{m}$ in diameter before testing. As a result, the measured diameters were more representative of the real contact geometry, notwithstanding the fact that these were measured following 10 revolutions (rather than 1 ).

A transition in the wear mode observed was expected to occur as the load and slurry volume fraction was varied and indeed, Fig. 4 shows that the results attained fit well within those predicted by the Adachi and Hutchings model. Fig. 4 also illustrates the difficulty encountered in trying to achieve a $3 \mathrm{~B}$ wear mode using alumina as the abrasive medium. The much finer alumina particles increase the severity of contact resulting in 2B grooving. Finally, the figure also gives an indication of the possible changes in wear mode when testing coated and diffusion-treated Ti-6Al-4V. In these cases, the increase in hardness of the surface material may shift the testing region closer to the transition line and thus some grooving may be observed.

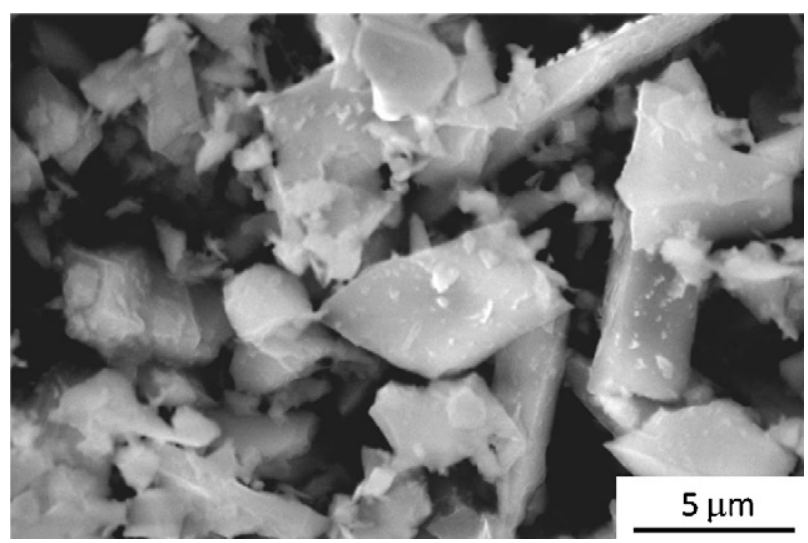

Fig. 5. SEM micrograph of P1200 grade SiC particles used as abrasive for microabrasion tests. The SiC particles are angular with an evident plate-like morphology. 


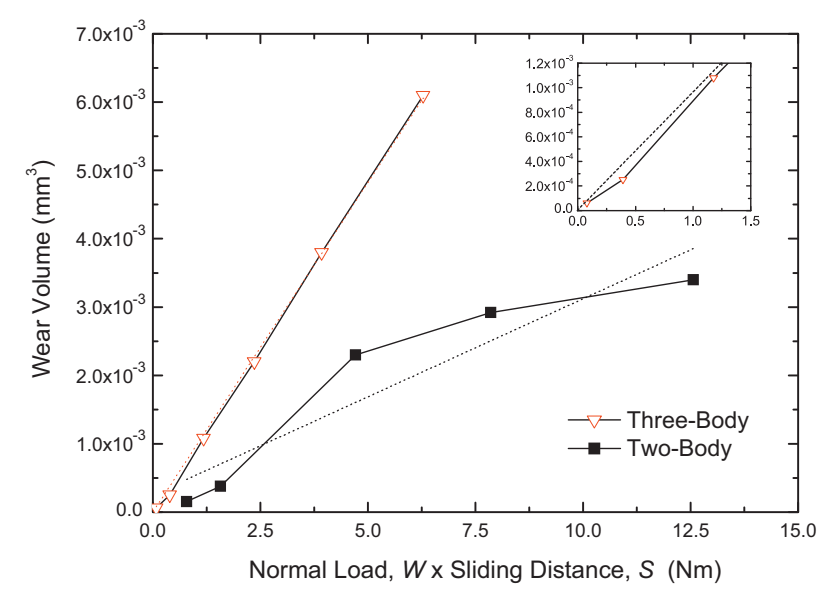

Fig. 6. Variation of wear volume, $V$, with the product of normal load, $W$, and sliding distance, $S$, for two-body abrasion $\left(V_{f}=0.06\right.$ and $\left.W=0.2 \mathrm{~N}\right)$ and three-body abrasion $\left(V_{f}=0.24\right.$ and $\left.W=0.1 \mathrm{~N}\right)$ on untreated Ti-6Al-4V using SiC slurry. Superimposed are linear fits (dotted) for the same data. Insert shows 3B data only.

The last criterion to consider for selecting the testing parameters, particularly for a homogeneous material (in this case the untreated Ti alloy), is the wear volume, $V$, generated which should be proportional to the load, $W$, and sliding distance, $S$, used. In other words, Archard's equation (Eq. (5)) for sliding wear should in theory be satisfied. Fig. 6 shows data generated when testing the substrate material using different loads and sliding distances. The 3B rolling data suggests that $V$ is indeed directly proportional to the product of $S$ and $W$, with a coefficient of determination $(C O D)>0.9995$. On the other hand, the data for $2 \mathrm{~B}$ grooving abrasion shows a nonlinear correlation. The measured scar volume is reduced as increased pressure in the wear contact discourages particle entrainment [20]. In agreement with other published literature [5], these results demonstrate that the data generated by a $3 \mathrm{~B}$ wear mechanism is therefore more suitable to provide a wear coefficient value, $\kappa$, for micro-abrasive testing of Ti-6Al-4V.

Based on the results explained earlier, all successive experiments were performed using SiC slurry, at a normal load of $0.1 \mathrm{~N}$ and at a volume fraction of 0.24 . In addition, a relatively slow ball rotation speed was maintained - since more severe hydrodynamic interactions between the slurry and the sample surface also tend to promote grooving [2]. The rotational speed was set to approximately $76 \mathrm{rpm}$, equivalent to a tangential linear velocity of $0.1 \mathrm{~m} / \mathrm{s}$.

As a benchmark for the abrasion resistance of the untreated Ti-6Al-4V alloy, the value of $\kappa_{s}$ was determined from the gradient of a linear fit to the 3B data plotted in Fig. 6. The fitted line was deliberately 'forced' through the origin since this improves the reliability of the data by reducing the influence of outlying data points [8]. Although the high COD value obtained indicates that the linear regression equation is very accurate, a minor deviation from the linear fit of the data points closest to the origin can be observed in the insert shown in Fig. 6. This is likely to be caused by the existence of different wear mechanisms in the initial part of the test, when the sample surface is still almost completely flat. This may also be related to (i) a shallow work hardened layer at the surface of the samples caused by the metallographic preparation route and (ii) increased particle slip on the initially highly polished surface. Both of these factors lead to a reduction in the wear coefficient and this is reflected in a lower apparent gradient at the origin of the curve.

\subsection{Triode plasma diffusion-treated samples}

The hardness-depth profiles of Ti-6Al-4V subjected to three different triode plasma diffusion treatments are shown in Fig. 7.

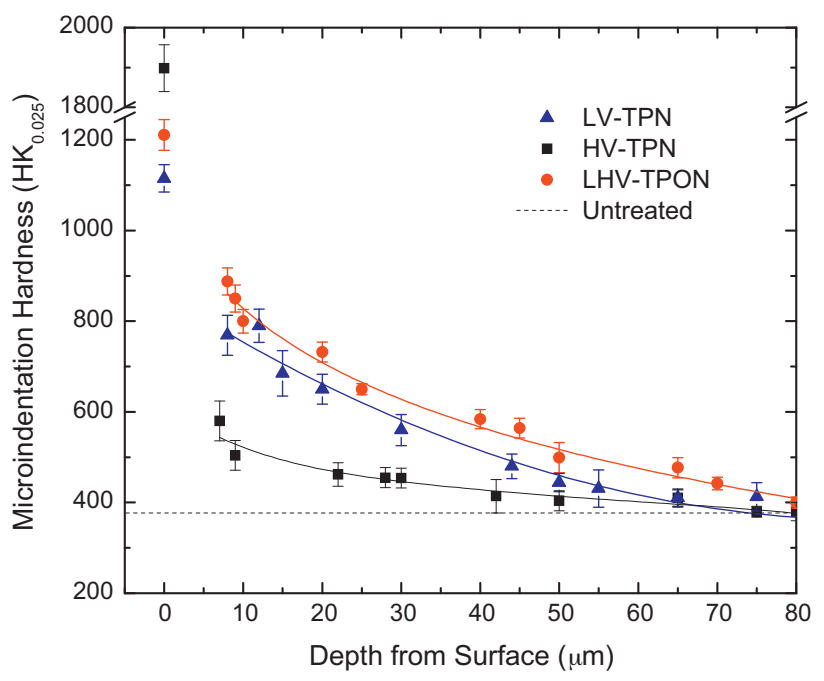

Fig. 7. Hardness-depth profiles of diffusion-treated Ti-6Al-4V samples. All treatments were carried out at $700^{\circ} \mathrm{C}$ for a total of $4 \mathrm{~h}$. The high voltage stage in both HV-TPN and LHV-TPON, and the oxidation stage in the latter lasted for $1 \mathrm{~h}$.

All three treatments, shown in the figure, result in an increase in the hardness of the alloy down to several tens of microns into the bulk. However, some differences can be observed. The nitrogen diffusion-strengthened zone in LV-TPN-treated samples is significantly larger than in HV-TPN while, conversely, the surface hardness measured in latter is around 70\% higher than in the former. This results from the fact that HV-treatments generate a thicker nitride compound layer $(1.45 \pm 0.1 \mu \mathrm{m}$ compared to $0.25 \pm 0.1 \mu \mathrm{m}$ for LV-TPN after $4 \mathrm{~h}$ ), which acts as a barrier to further nitrogen diffusion $[21,22]$. The effect of these treatments on the tribological properties of Ti-6Al-4V has been discussed in detail in [1]. The tribological performance of LV-TPN-treated Ti-6Al-4V was shown to be greatly superior to that obtained by HV-TPN under equivalent conditions of time and/or temperature. For this reason lower voltage treatments, capable of providing a deep hardened case (and in turn better load support to the subsequently deposited coating), were favoured for micro-abrasion testing.

In addition, the introduction of oxygen during the first hour of the treatment was used to further increase the hardened case depth. The rate of oxygen diffusion in $\alpha$-Ti is known to be much higher than that of nitrogen at a given temperature [21,23] and can also (unlike in the case of nitriding processes) be maintained at its maximum potential - irrespective of the formation of an oxide layer during the oxidation process. In the case of LHV-TPON this was also combined with a final hour of nitriding at a cathode bias of $-1000 \mathrm{~V}$, which was intended to promote the formation of TiN/ $/ \mathrm{Ti}_{2} \mathrm{~N}$ at the surface, thereby further increasing the surface hardness and the adhesion strength of the PVD coating (by improving chemical affinity). The resulting hardness-depth profile of the improved LHVTPON is clearly superior to that of the benchmark LV-TPN-treated sample (Fig. 7).

Determining the effect of different diffusion treatments on the abrasion resistance of these alloys posed several difficulties. Firstly, unlike coatings there is no clear boundary between the hardened layer and the substrate material; instead, the material chemistry and mechanical properties vary gradually from the surface compound layer to the bulk. Secondly, different treatments result in different compound layer characteristics and different thicknesses and in turn these layers are mechanically supported by varying case depths. This implies that the specific wear rate of diffusion-treated material should be considered as a complex variable which changes with depth. As a result, analytical methods used for coated samples could not be directly employed in this work. However, since in most 
Table 3

Wear coefficients of Ti-6Al-4V surfaces subjected to various diffusion treatments.

\begin{tabular}{llc}
\hline Sample & $\begin{array}{l}\text { Wear coefficient } \\
\left(\times 10^{-4} \mathrm{~mm}^{3} / \mathrm{Nm}\right)\end{array}$ & $\begin{array}{l}\Delta \kappa, \% \text { (compared to } \\
\text { untreated) }\end{array}$ \\
\hline Untreated & 9.65 & - \\
LV-TPN $(4 \mathrm{~h})$ & 8.98 & -6.9 \\
LHV-TPON $(4 \mathrm{~h})$ & 8.67 & -10.1 \\
\hline
\end{tabular}

cases the depth of penetration of the rotating ball into the substrate remains within the region strengthened by the plasma treatment - the penetration at 800 revolutions is of the order of $12 \mu \mathrm{m}$ - it was decided that to rank the efficacy of these treatments it was sufficient to consider the material sampled by the test as uniform.

The wear coefficients were obtained from fitting lines to plots of $V$ vs. WS for several samples. The gradients of the linear regression lines are tabulated in Table 3 together with the percentage change in micro-abrasion wear coefficient. Both treated samples showed some degree of improvement corresponding to negative percentile changes. However, an initially higher wear rate, compared to the untreated material, was measured for 10,35 and 50 revolution tests. The initial poor performance of the triode plasma treated alloy can be related to the increased surface roughness following treatment. For instance, the $R_{a}$ values measured for LV-TPN and LHV-TPON samples were 0.05 and $0.08 \mu \mathrm{m}$ respectively, compared to $0.03 \mu \mathrm{m}$ for the polished untreated alloy. The higher $R_{a}$ values may increase the instantaneous wear coefficient at the beginning of the test by reducing the real contact area, thereby increasing the local contact stresses. The roughness of these samples eventually decreases and the gradient of the $V$ vs. WS plot is consequently reduced - indicating a lower wear coefficient.

\subsection{Single-layered coated samples}

Since the value of $\kappa_{S}$ was pre-determined, the Hedenqvist method [8,24] could have been used to directly obtain a value of $\kappa_{c}$ from a plot of ( $W S-V_{S} / \kappa_{S}$ ) against $V_{c}$ (Eq. (6)). However, the Rutherford method [10], which uses the inverse values of the intercept and slope of a single plot of $W S / V$ vs. $V_{c} / V$ (Fig. 8) to determine $\kappa_{s}$ and $\kappa_{c}$, was chosen. The Rutherford method is preferred since the values of $\kappa_{S}$ obtained are considered to be more representative of the actual material below the coating which, although virtually identical to the untreated material, may still show different wear resistance when in the presence of a hard PVD deposit. Furthermore, the volume measurements obtained for the shorter tests - during which the coating was not perforated - were used to plot graphs similar to Fig. 6 from which $\kappa_{c}$ values were calculated.

The wear coefficients obtained from fitting lines to the data obtained by 3D profilometry are shown in Table 4 . The wear coefficient for the TiN coating shows a significantly higher resistance to micro-abrasion compared to the uncoated substrate. This value of $\kappa_{c}$ is also in very good agreement with that obtained by non-perforating tests. It should be highlighted that the wear scar topography did not change between shorter (non-perforating) and longer (perforating) tests, suggesting the same abrasive wear mode in both cases. Furthermore, the 3D mapping and subsequent volume measurements of small scars, such as those needed for non-perforating tests, are clearly sufficiently accurate to produce comparable results. The 3D volume obtained removes concerns

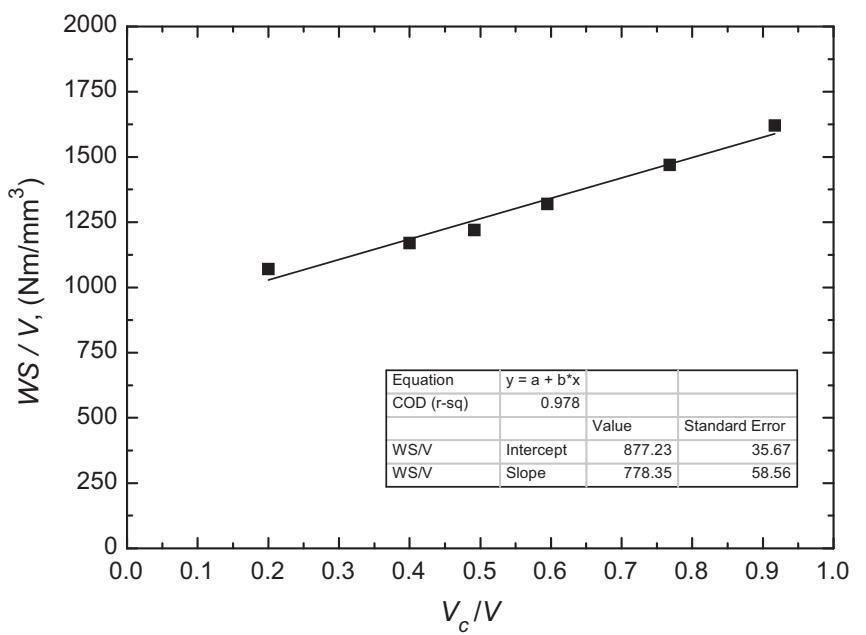

Fig. 8. Linear plot of $W S / V$ against $V_{c} / V$ for single layered TiN deposited on Ti-6Al-4V used to apply Rutherford analysis method.

related to the accuracy of the hemi-spherical shape of the scar, which more often than not deviates considerably, particularly in the early stages of the test. Thus, if only $\kappa_{c}$ is needed, confining the scar to the coating thickness by using short micro-abrasion runs is clearly advantageous, since the test (and the subsequent scanning profilometry) is relatively rapid - and the results obtained are sufficiently accurate.

Interestingly, the wear rate of the substrate also changes, depending on the conditions under which it was measured. An increase in $\kappa_{s}$ following the deposition of a TiN ceramic coating has also been observed by Batista et al. $[25,26]$ for single-layer coated and duplex-treated AISI H13 steel. This can be related to the generation of hard coating debris, which acts as a source of additional wear particles, thus increasing abrason of the substrate. However, it may also be related to differences in scar development with increasing number of revolutions, depending on whether or not the substrate has been coated. For instance, the presence of a TiN coating inhibits formation of an annulus of piled-up material around the crater, which is always present in the untreated material (and may affect the flow of SiC particles inside the scar).

The wear coefficient was also measured for $\mathrm{CrAlN}$ and was found to be significantly smaller than that of TiN (Table 4). Although the micro-abrasion resistance of the two coatings appears to be related to their hardness it does not follow a simple $1 / H_{c}$ trend as predicted by Archard [27]. A film designed to resist micro-abrasive wear must indeed have high hardness to resist scratching and ploughing but must also have a low elastic modulus to resist plastic deformation during contact against a counterface [28]. A material with a lower Young's modulus can also elastically deform to distribute the contact load over a larger area, thereby reducing the maximum contact pressure. Tsui et al. [29] showed that the resistance to plastic deformation is dependent on the ratio $H^{3} / E^{2}$. Thus, the contact loads required to induce plastic deformation in materials with high hardness and low elastic modulus (i.e. a high $H^{3} / E^{2}$ ratio) are higher. In this case, the $H^{3} / E^{2}$ parameter is 0.28 for CrAlN and 0.08 for TiN. Consequently the higher resistance to yielding of the CrAlN film appears to be a major contributory factor to its

Table 4

Wear coefficients of Ti-6Al-4V substrate and single-layered coatings.

\begin{tabular}{|c|c|c|c|}
\hline Sample & $\kappa_{s}\left(\times 10^{-4} \mathrm{~mm}^{3} / \mathrm{Nm}\right)$ & $\kappa_{c}\left(\times 10^{-4} \mathrm{~mm}^{3} / \mathrm{Nm}\right)$ & $\kappa_{c}($ non-perforating $)\left(\times 10^{-4} \mathrm{~mm}^{3} / \mathrm{Nm}\right)$ \\
\hline Single-layered TiN & 11.39 & 6.01 & 6.91 \\
\hline Single-layered $\mathrm{CrAIN}$ & 11.52 & 1.06 & 2.07 \\
\hline Single-layered WC/C & 9.59 & 45.88 & 61.21 \\
\hline
\end{tabular}




\section{No. of Ball \\ Revolutions}

50

100

150

300

500

800
TiN
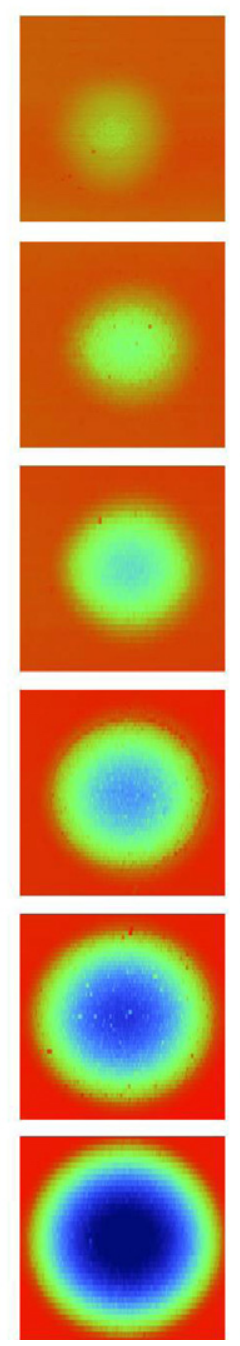

CrAIN
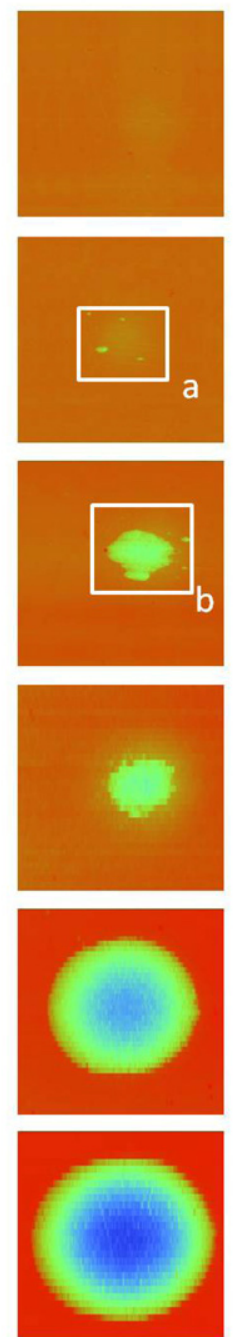

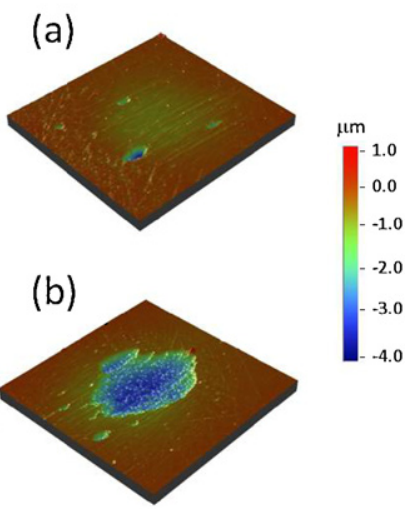

$\mu \mathrm{m}$
-2.0
-0.0
-2.0
-4.0
-6.0
-8.0
-10.0

$1 \mathrm{~mm}$

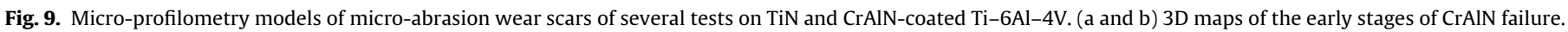

remarkable performance. This is also in agreement with recent work on abrasion resistance by Zok and Miserez [30], who demonstrated that the material with the highest value of $H^{3} / E^{2}$ can better resist the initiation of cracking damage. The sharp contact generated by the abrading particles and the resultant coefficient of friction of $\sim 0.25[4,10]$ under the test conditions used in the present work dictate that cracking, as opposed to yielding, initiates failure of these ceramic coatings [30].

The superior resistance of CrAlN to abrasive wear is more evident when observing the abrasion scars formed after increasingly longer tests. The wear scar produced on TiN-coated Ti-6Al-4V is almost identical to that observed on the untreated alloy; albeit there is no discernable material pile-up around the edges of the scar. On the other hand, CrAIN seems to fail under micro-abrasion testing in a different manner. Fig. 9 shows that the formation of a wear scar is considerably delayed and no appreciable signs of wear can be seen for up to 50 ball revolutions in the case of CrAlN. Stylus profilometry shows that the overall wear depth is in fact less than $0.1 \mu \mathrm{m}$ for up to 75 ball revolutions. However, once the 100 revs mark is reached a different mechanism becomes evident - local areas of through-thickness failure appear - well before the rest of the coating has been worn through. These regions rapidly increase in number and size with increasing ball revolutions, exposing the underlying material. Also evident are aligned grooves parallel to the direction of ball rotation - a characteristic of $2 \mathrm{~B}$ sliding abrasion.
The hard CrAlN surface changes the dominant wear mode by moving the operating region of this test to higher $H_{s} / H_{b}$ values across the transition line (Fig. 4). The SiC particles can then plough into the material - fracturing the coating and initiating grain pull-out. Unlike in the case of the untreated metal, 2B abrasion appears to have much more deleterious consequences and leads to a measurable increase in wear rate. These failed coating regions eventually gradually grow and coalescence until the ball perforates completely though the coating. At this stage, the wear scar starts to follow more closely the imposed hemispherical shape of the ball and, as the test severity diminishes, the principal wear mode becomes 3B.

A change in wear mechanism is also a plausible explanation of the systematic deviation observed between the wear rates measured for perforating and non-perforating tests for both TiN and CrAlN [16]. Although the test parameters remained unchanged, the coating material experienced a different wear mechanism, starting from $2 \mathrm{~B}$ (when the coating still covered the entire wear scar), changing into mixed mode (when the substrate was exposed) and finally changing into 3B system (when the scar was sufficiently large). The final transition typically occurred between 150 and 300 ball revolutions. This is a likely cause of the differences between specific wear rates measured using perforating and non-perforating tests. A transition in the dominant wear mode or simply a moderate change in contact pressure - may reduce the wear rate as a function of sliding distance. By definition, 


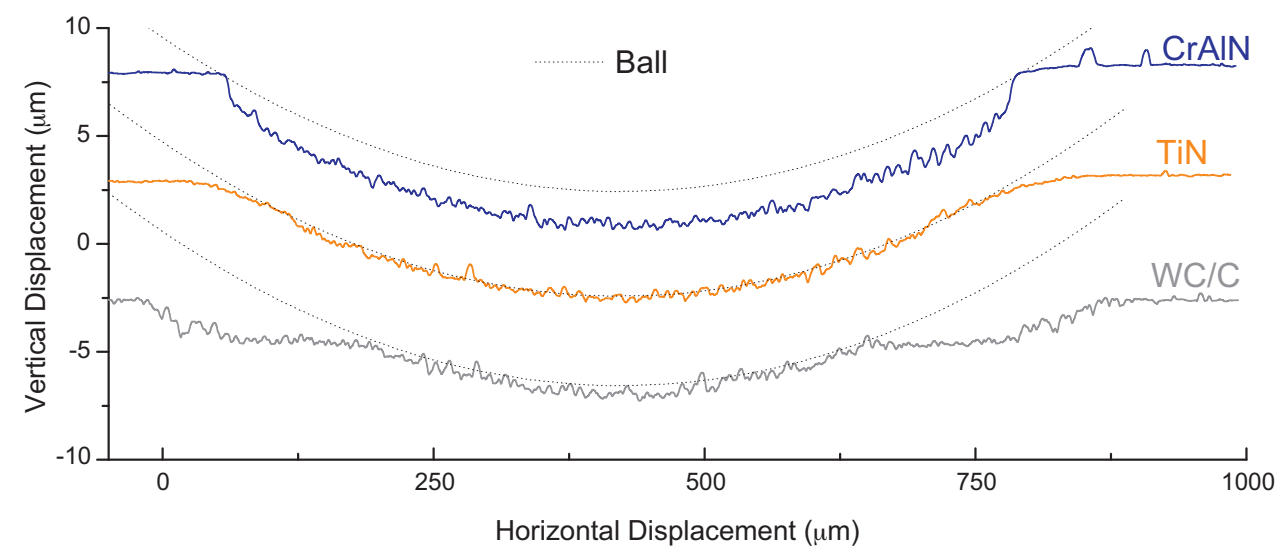

Fig. 10. 2D profiles of micro-abrasion wear scars for CrAIN (150 revs), TiN ( 150 revs) and WC/C ( 50 revs) deposited on Ti-6Al-4V. Dotted lines represent the ball surface.

non-perforating tests are always shorter than perforating ones and therefore a higher average coating wear coefficient for nonperforating tests is likely to be observed. Therefore the results obtained through perforating tests can be considered as more truly representative of the coating performance as these are predominantly determined by $3 \mathrm{~B}$ wear data. For the same reason, the correlation coefficient of plots obtained from perforating data was often higher - typically ranging between 0.92 and 0.98 . This is a clear indication of less statistical variance of $3 \mathrm{~B}$ data, which is a result of the relative insensitivity of rolling abrasion to varying test conditions [5].

Such differences between perforating and non-perforating tests have already been observed [31]; however, these have previously been attributed to the scar volume estimation method (and the error involved). The measurement method adopted in the present work guarantees that these differences are not an artefact of the volume estimation process but are indeed a 'real' effect in the wear scars. In fact, the 3D model allows the determination of the crater volume without needing to specify the crater boundary. Instead, the volume is demarked by the original sample surface as a reference plane. Any edge rounding and/or material pile-up that occurs does not distort the measured value.

Looking at the $\kappa_{s}$ value obtained by testing single-layered CrAlN, it seems (as in the case of TiN-coated Ti alloys) that CrAlN affects the resistance of the substrate to abrasive wear. In fact, a slight increase in $\kappa_{S}$ is noticeable - presumably due to the higher hardness of CrAlN. However, the significantly harder coating (and resulting debris) did not lead to much higher substrate wear rates. This can be explained by the counteracting effect created by the wear resistant coating. The edges of the wear scar do not wear rapidly enough to replicate the ball surface and therefore force the ball to remain slightly removed from the sample surface (Fig. 10). This is likely to reduce the pressure on the central, softer untreated portion of the scar, thereby producing a lower wear coefficient.

WC/C exhibited behaviour almost completely the opposite to that of CrAlN. The $\kappa_{c}$ value measured for WC/C was much higher than that of the untreated Ti alloy. Table 4 gives the coating and substrate wear coefficient values, including those measured from non-perforating tests - which in this case had to be particularly brief ( $<10$ revs). The exceptionally high wear coefficient is indicative of how rapidly the ball wears through the coating. In fact, the $\kappa_{s}$ value is unaffected by the presence of the coating and its value is almost identical to that of the uncoated substrate.

Tribological testing has often demonstrated that $\mathrm{WC} / \mathrm{C}$ coatings can provide outstanding wear resistance [32,33]; typically, WC/C shows a relatively good resistance to sliding wear, superior to that of TiN-coated samples. The poor performance shown here emerges from differences in test configuration compared to, say, dry sliding in pin-on-disc or reciprocating ball-on-flat testing. Firstly, the ability of $\mathrm{WC} / \mathrm{C}$ to reduce the wear rate is largely governed by its ability to form a lubricious transfer layer - which is unlikely to occur under particulate abrason test conditions. Secondly, most testing performed on WC/C-coated material is principally $2 \mathrm{~B}$ while, in this case, material loss is caused by the penetration of abrasive particles (third body) causing micro cutting and chipping. Thus for a film to resist abrasive wear its hardness and its toughness are most important. The WC/C film tested here did not exhibit high hardness values probably due to the high hydrogen content, exceeding $15-20 \%$, and therefore a good resistance to abrasive wear was not expected. Nanoindentation results show that the hardness of WC/C was only $14.3 \pm 1.3 \mathrm{GPa}$ compared to $26.3 \pm 4 \mathrm{GPa}$ and $33.5 \pm 3 \mathrm{GPa}$ for TiN and CrAlN respectively. The two ceramic nitride coatings are harder than the abrasive $\mathrm{SiC}$ particles (the latter with a hardness of 24.5 GPa [19]) and are therefore able to better resist penetration. Furthermore, the increase in wear coefficient to values higher than that of the substrate can be explained by a relatively poor coating adhesion (compared to that of TiN and CrAlN), leading to coating delamination and also by the presence of softer regions with predominantly $\mathrm{sp}^{2}$-hybridised bonding character in the coating (with a local hardness of only $\sim 2.5 \mathrm{GPa}$ ). Fig. 10 shows how the coating outside the region of direct contact with the ball-carrier fluid has also failed. This extent of coating loss around the crater edge shows that $\mathrm{WC} / \mathrm{C}$ is easily removed from the substrate by just the turbulent flow of SiC particles around the contact area.

\subsection{Duplex-treated samples}

Both diffusion-treated and coated samples have been shown to provide some degree of protection against abrasive wear. Table 5 gives the micro-abrasion wear coefficients of selected samples that had been diffusion-treated and subsequently coated.

Comparing the wear coefficients of LHV-TPON-treated samples shown in Table 5 and single layered TiN and CrAlN shown in Table 4 demonstrates that the $\kappa_{C}$ of both coatings can be reduced when the coating is deposited on a previously diffusion-treated surface. This indicates that the wear coefficient value of a coating measured using micro-abrasion testing is indeed affected by the properties of the underlying substrate, as suggested by Batista et al. [34]. Although the micro-abrasion test was devised specifically to provide coating wear coefficients that are independent from the underlying material, this work shows that there seems to be significant evidence to support the claim that the coating wear coefficient may be affected by the nature of the underlying substrate. The reason for the dependency is, for the duplex 
Table 5

Wear coefficients of Ti-6Al-4V substrate and duplex coatings.

\begin{tabular}{|c|c|c|c|}
\hline Sample & $\kappa_{s}\left(\times 10^{-4} \mathrm{~mm}^{3} / \mathrm{Nm}\right)$ & $\kappa_{c}\left(\times 10^{-4} \mathrm{~mm}^{3} / \mathrm{Nm}\right)$ & $\kappa_{c}$ (non-perforating) $\left(\times 10^{-4} \mathrm{~mm}^{3} / \mathrm{Nm}\right)$ \\
\hline HV-TPN $(4 \mathrm{~h})+\mathrm{TiN}$ & 16.19 & 7.21 & 7.91 \\
\hline LHV-TPON $(4 \mathrm{~h})+\mathrm{TiN}$ & 11.30 & 5.15 & 6.22 \\
\hline LHV-TPON $(12 \mathrm{~h})+\mathrm{TiN}$ & 10.90 & 4.11 & 5.01 \\
\hline LHV-TPON $(4 \mathrm{~h})+$ CrAlN & 12.02 & 0.44 & 1.43 \\
\hline
\end{tabular}

diffusion/coating treatments reported here, likely to be related to the presence of a hard compound layer created during the thermochemical treatment stage. The effect of the diffusion treatment is mostly noticeable in the $\kappa_{c}$ value; there is less change in $\kappa_{S}$ compared to previous values obtained from single-layered coatings (Table 4). The beneficial effect of the substrate pretreatment on the coating micro-abrasion resistance is again confirmed by the extended LHV-TPON process. This treatment was carried out for a total of $12 \mathrm{~h}$ in order to obtain a deeper hardened case and therefore better load support for the TiN coating. Once again, the wear coefficient for the TiN coating was lower than when deposited on an untreated substrate, but was also lower following a shorter $4 \mathrm{~h}$ substrate pretreatment process. Clearly, enhanced compound layer formation, together with a deeper diffusion case, results in a greater reduction in the coating wear coefficient.

When diffusion-treated samples are tested without the presence of a coating, the improved wear resistance can be directly attributed to the surface treatment; however, when these samples are tested with a duplex treatment the improvement achieved is observable primarily in the $\kappa_{c}$ value as the compound layer formed appears to act as if incorporated into the PVD coating. The much larger underlying diffusion zone is also considerably softer in comparison and so does not lead to a tangible reduction in $\kappa_{s}$. Furthermore, a very significant improvement in adhesion strength has been measured for PVD coatings with prior nitrogen diffusion treatment of the substrate. Micro-scratch adhesion tests show an increase in the load necessary to induce adhesive failure from $11 \mathrm{~N}$ to $44 \mathrm{~N}$ for single-layered TiN and LHV-TPON + TiN samples respectively [35]. This is also likely to inhibit coating failure during micro-abrasion testing. In fact, the failure mechanism previously described for CrAlN, involving through-thickness local failure regions, was not observed in duplex samples and the scar growth appeared to progress uniformly until the coating is completely penetrated.

The above suggests that diffusion treatments yielding high surface hardness values (HV-TPN type) should provide greater improvements in tribological performance compared to treatments which favour increased case depth (TPON type). However, HV treatments also increase the surface roughness considerably ( $R_{a}=0.11 \mu \mathrm{m}$ following a $4 \mathrm{~h}$ treatment) and therefore lead to higher local contact pressures. In addition, the hard nitride compound layer created is likely to be more brittle and susceptible to fatigue failure, which in turn is more relevant when the underlying material is prone to significant elastic deformation under repetitive loading. This has a negative effect on the coating wear coefficient as can be seen more clearly from the increased $\kappa_{c}$ of the duplex TiN-coated HV-TPN sample (Table 5). Similarly, work by Schiffmann et al. [16] has shown a higher average wear coefficient for TiN deposited on a ground Ti alloy substrate, compared to that of polished alloy. A similar increase in specific wear rate can be observed for the substrate, where hard nitride debris accelerates the wear rate of the exposed portion of the substrate. As a result, extended treatments, which create a more gradual mechanical gradient, should be favoured to avoid such consequences. In this study, the LV diffusion treatments were completed by only a short (i.e., $1 \mathrm{hr}$ ) HV nitriding stage, to increase the surface hardness - while at the same time optimising the overall treatment depth obtained.

\section{Conclusions}

Micro-abrasion wear testing was used to evaluate the wear resistance of triode plasma diffusion-treated, single-layer TiN-, CrAlN- and WC/C-coated and duplex-treated Ti-6Al-4V. Perforating and non-perforating tests were performed on different treatment combinations using optimised test parameters which had been determined. Furthermore, 3D wear scar mapping generated by mechanical profilometry was used to measure accurately the scar volumes. The following conclusions can be drawn:

- The optimum micro-abrasion test conditions for repeatable 3B abrasion of Ti-6Al-4V were found to be low loads $(\sim 0.1 \mathrm{~N})$, high abradant volume fractions ( $\sim 0.24$ solid content), and a sliding velocity of $0.1 \mathrm{~m} / \mathrm{s}$, combined with relatively coarse SiC powder as the abrasive medium. The resultant severity of contact in 3B rolling abrasion was shown to provide a stable wear coefficient.

- In order to avoid large errors in the crater volume measurements, particularly in cases where the wear coefficient of substrate and coating differ considerably, 3D models generated through profilometry (mechanical or otherwise) are preferable.

- Perforating tests have been shown to be less susceptible to changes in contact area and abrasion mode. Thus, in order to achieve consistent and comparable wear coefficients, relatively longer tests ( $>10 \mathrm{~m} / 150$ ball revolutions) should be performed.

- Triode plasma diffusion treatments alone are capable of reducing the specific wear rate of Ti alloys - although the increase in surface roughening typical of these treatments should be minimised wherever possible.

- Testing of PVD coatings alone has shown that the deposition of a suitably hard and tough PVD layer can provide excellent short-term protection against third body particulate abrasion. Single-layered TiN reduced the wear coefficient by around 60\% while single-layered $\mathrm{CrAlN}$ reduced it by more than $800 \%$. Conversely, lubricious $\mathrm{WC} / \mathrm{C}$ did not provide significant protection to the underlying substrate material.

- Substantial changes in the substrate wear coefficient were noted, depending on the coating deposited. This was correlated with the presence of hard coating debris, together with resultant changes in wear scar geometry and progression, compared to untreated Ti-alloy.

- Almost all duplex diffusion/coating treatments showed further significant reductions in their $\kappa_{c}$ values - which can be attributed primarily to the presence of a hard compound layer (and improved load-bearing capacity as a result). This reduction in $\kappa_{c}$ however excludes duplex samples, where the coating had been deposited following a nitriding cycle at high bias voltage only (HV-TPN). This was related to excessive roughening and embrittlement of the surface under these treatment conditions.

- Although diffusion-treated samples apparently exhibit higher abrasive wear resistance when tested without a coating, this does not translate into a lower substrate wear coefficient when tested in the duplex condition. It appears that the improvement is related to the fact that the compound layer generated is 'seen' by the test as being integral with the PVD ceramic coating and thus its contribution to wear resistance is not reflected in the treated substrate wear coefficient measurements. 


\section{Acknowledgements}

The authors gratefully acknowledge financial support for this research work from the UK Technology Strategy Board, under Technology Programme project TP/22076, in collaboration with Tecvac Ltd., NMB-Minebea UK Ltd. and Airbus UK.

\section{References}

[1] G. Cassar, J.C. Avelar-Batista Wilson, S. Banfield, J. Housden, A. Matthews, A. Leyland, Wear 269 (2010) 60-70.

[2] K. Bose, R.J.K. Wood, Wear 258 (2005) 322-332.

[3] R.I. Trezona, D.N. Allsopp, I.M. Hutchings, Wear 225-229 (1999) 205-214

[4] E. Rabinowicz, L.A. Dunn, P.G. Russell, Wear 4 (1961) 345-355.

[5] K. Adachi, I.M. Hutchings, Wear 258 (2005) 318-321.

[6] D.N. Allsopp, R.I. Trezona, I.M. Hutchings, Tribol. Lett. 5 (1998) 259-264.

[7] K. Adachi, I.M. Hutchings, Wear 255 (2003) 23-29.

[8] Y. Kusano, K. Van Acker, I.M. Hutchings, Surf. Coat. Technol. 183 (2004) 312-327.

[9] K.L. Rutherford, I.M. Hutchings, J. Test. Eval. 25 (2) (1997) 250-260.

[10] K.L. Rutherford, I.M. Hutchings, Surf. Coat. Technol. 79 (1996) 231-239.

[11] A. Leyland, K.S. Fancey, A. Matthews, Surf. Eng. 7 (3) (1991) 207-215.

[12] A. Leyland, K.S. Fancey, A.S. James, A. Matthews, Surf. Coat. Technol. 41 (1990) 295-304.

[13] BS EN ISO 4545-1, Metallic materials - Knoop hardness test - Part 1: Test method, 2005, BSi, 1-14.

[14] BS ISO 26424, Fine ceramics (advanced ceramics, advanced technical ceramics) - determination of the abrasion resistance of coatings by a microscale abrasion test, BSi, 2008, 1-15.
[15] P.H. Shipway, J.J. Hogg, Wear 263 (2007) 887-895

[16] K.I. Schiffmann, R. Bethke, N. Kristen, Surf. Coat. Technol. 200 (2005) $2348-2357$.

[17] V. Imbeni, C. Martini, E. Lanzoni, G. Poli, I.M. Hutchings, Wear 251 (2001) 997-1002.

[18] A. Kassman, S. Jacobson, L. Erickson, P. Hedenqvist, M. Olsson, Surf. Coat. Technol. 50 (1991) 75-84.

[19] G.S. Brady, H.R. Clauser, J.A. Vaccari, Materials Handbook, 15th edition, McGraw Hill, 2002, pp. 42, 844.

[20] R.I. Trezona, I.M. Hutchings, Wear 233-235 (1999) 209-221.

[21] F.W. Wood, O.G. Paasche, Thin Solid Films 40 (1977) 131-137.

[22] N. Kashaev, H.-R. Stock, P. Mayr, Met. Sci. Heat Treat. 46 (7-8) (2004) 294-298.

[23] J. Unnam, R.N. Shenoy, R.K. Clark, Oxid. Met. 26 (3/4) (1986) 231-252.

[24] E. Bergmann, P. Hedenqvist, M. Bromark, M. Olsson, S. Hogmark, Surf. Coat. Technol. 63 (1994) 115-122.

[25] J.C.A. Batista, C. Godoy, A. Matthews, Tribol. Int. 35 (2002) 363-372.

[26] J.C.A. Batista, A. Matthews, C. Godoy, Surf. Coat. Technol. 142-144 (2001) 1137-1143.

[27] J.F. Archard, Proc. R. Soc. Lond. A 243 (1957) 190-205.

[28] J. Musil, Surf. Coat. Technol. 125 (2000) 322-330.

[29] T.Y. Tsui, G.M. Pharr, W.C. Oliver, C.S. Bhatia, R.L. White, S. Anders, A. Anders, I.G. Brown, Mater. Res. Soc. Symp. Proc. 383 (1995) 447-452.

[30] F.W. Zok, A. Miserez, Acta Mater. 55 (2007) 6365-6371.

[31] A. Ramalho, Surf. Coat. Technol. 197 (2005) 358-366.

[32] K. Bobzin, N. Bagcivan, N. Goebbels, K. Yilmaz, B.-R. Hoehn, K. Michaelis, M. Hochmann, Surf. Coat. Technol. 204 (2009) 1097-1101.

[33] R.J. Rodriguez, J.A. Garcia, R. Martinez, B. Lerga, M. Rico, G.G. Fuentes, A. Guette, C. Labruguere, M. Lahaye, Appl. Surf. Sci. 235 (2004) 53-59.

[34] J.C.A. Batista, M.C. Joseph, C. Godoy, A. Matthews, Wear 249 (2002) 971-979.

[35] G. Cassar, S. Banfield, J.C. Avelar-Batista Wilson, J. Housden, A. Matthews, A. Leyland, Surf. Coat. Technol. 206 (2011) 395-404. 